\title{
A comunicação, o consumo e a sustentabilidade: Uma análise sob a ótica ambiental
}

\author{
Communication, consumption and sustainability: An analysis from the environmental perspective \\ Comunicación, consumo y sostenibilidad: Un análisis desde la perspectiva ambiental
}

Recebido: 28/06/2021 | Revisado: 04/07/2021 | Aceito: 06/07/2021 | Publicado: 15/07/2021

\author{
Ricardo Costa \\ ORCID: https://orcid.org/0000-0003-1434-9695 \\ Universidade Paulista, Brasil \\ E-mail: ricardo.costa@ung.br \\ Márcio Magera Conceição \\ ORCID: https://orcid.org/0000-0001-6477-4580 \\ Universidade de Guarulhos, Brasil \\ E-mail:magera@uol.com.br \\ Joelma Telesi Pacheco Conceição \\ ORCID: https://orcid.org/0000-0002-7045-6260 \\ Universidade de Guarulhos, Brasil \\ E-mail: joelma.telesi@gmail.com
}

\begin{abstract}
Resumo
O consumo e a sustentabilidade são temas atuais em nossa sociedade que acende um problema latente e que tem trazido à tona uma discussão sobre a importância quanto à conscientização do consumo sustentável. Fazemos parte de um ecossistema que a cada dia gera um afastamento, muitas vezes, involuntário de nosso verde. Sem perceber, a comunicação das empresas focada na busca de melhores resultados incentiva o consumo acelerado como forma de gerar maiores lucros e "aquecendo" as vendas de seus produtos e serviços, sempre em ritmo de crescimento contínuo. A busca por lucros cada vez maiores ignora o fato básico de que a para atender a esta demanda, as empresas ignoram a preservação do planeta que não consegue se regenerar na mesma velocidade em que fornece a matéria prima necessária para atender a demanda destes produtos. Como aliado das empresas neste processo de incentivar o consumo, a comunicação estratégica mais eficiente e provida, cada vez mais, de canais específicos de interesses comuns, atingem de maneira mais assertivas seu público alvo, incentivando assim, o consumo ainda maior destes grupos. Desta forma, a necessidade de haver uma equação entre consumo e preservação ambiental, se faz presente para que exista um equilíbrio como fator determinante na conscientização dos consumidores em manter, de maneira sustentável, os recursos necessários para a sobrevivência da humanidade. A necessidade de utilizar a comunicação como fator preponderante com a importante função de gerar a conscientização das pessoas, e por consequência educar a população quanto à necessidade urgente sobre novos hábitos de consumo é fundamental para regenerar os prejuízos causados ao planeta ao longo do tempo.
\end{abstract}

Palavras-chave: Consumidor Verde; Sustentabilidade; Comunicação.

\begin{abstract}
Consumption and sustainability are a current theme in our society that sparks a latent problem in our society today, and that has brought up a discussion about the importance of raising awareness of sustainable consumption. We are all part of an ecosystem that every day generates an often involuntary departure from our green. Without realizing it, the communication of companies focused on the search for better results, encourages accelerated consumption as a way to generate greater profits and "heating up" the sales of their products and services, always at a pace of continuous growth. The search for ever-greater profits ignores the basic fact that to meet this demand, companies have been ignoring the preservation of the planet, which cannot regenerate at the same speed as it supplies the raw material needed to meet the production of these products. As an ally of companies in this process of encouraging consumption, strategic communication is more efficient and increasingly provided with specific channels of common interests, reaching its target audience more assertively, thus encouraging even greater consumption by these groups. In this way, the need to have an equation between consumption and environmental preservation, is present so that there is a balance as a determining factor in the awareness of consumers to maintain, in a sustainable way, the resources necessary for the survival of humanity. The need to use communication as a preponderant factor with the important function of generating people's awareness, and consequently, educating the population about the urgent need for new consumption habits is essential to regenerate the damage caused to the planet over time.
\end{abstract}

Keywords: Consumer Marketing; Sustainability; Communication. 


\begin{abstract}
Resumen
El consumo y la sostenibilidad son temas de actualidad en nuestra sociedad que encienden un problema latente y que han suscitado un debate sobre la importancia de concienciar sobre el consumo sostenible. Somos parte de un ecosistema que cada día genera una salida muchas veces involuntaria de nuestro verde. Sin darse cuenta, la comunicación de las empresas enfocadas en la búsqueda de mejores resultados incentiva el consumo acelerado como forma de generar mayores ganancias y "calentar" las ventas de sus productos y servicios, siempre a un ritmo de crecimiento continuo. La búsqueda de ganancias cada vez mayores ignora el hecho básico de que para satisfacer esta demanda, las empresas ignoran la preservación del planeta, que no puede regenerarse a la misma velocidad que suministra la materia prima necesaria para satisfacer la demanda de estos productos. Como aliado de las empresas en este proceso de fomento del consumo, la comunicación estratégica es más eficiente y cada vez más dotada de canales específicos de intereses comunes, llegando de forma más asertiva a su público objetivo, fomentando así aún un mayor consumo por parte de estos colectivos. De esta manera, se hace presente la necesidad de tener una ecuación entre consumo y preservación ambiental, para que exista un equilibrio como factor determinante en la conciencia de los consumidores para mantener, de manera sustentable, los recursos necesarios para la supervivencia de la humanidad. La necesidad de utilizar la comunicación como factor preponderante con la importante función de sensibilizar a las personas y, en consecuencia, educar a la población sobre la urgente necesidad de nuevos hábitos de consumo es fundamental para regenerar los daños ocasionados al planeta a lo largo del tiempo.
\end{abstract}

Palabras clave: Consumidor Verde; Sostenibilidad; Comunicación.

\title{
1. Introdução
}

Tudo que existe no planeta se comunica com algo. Quando vestimos para sair, nossa roupa transmite uma informação, quando decoramos as casas, apresentamos um estilo próprio para quem nos visita, até mesmo quando nascemos e choramos, estamos nos comunicando e transmitindo uma mensagem. A sociedade depende da comunicação para se manter "viva", transmitindo informações, fomentando nossa cultura e criando tradições através dos tempos.

A cultura capitalista, desenvolvida pela revolução industrial, acelerou o consumo de produtos e aliada ao crescimento e evolução dos requintes meios de comunicação, tornou o processo de consumo ainda mais eficaz, porém, na contramão deste processo, trouxe diversos problemas ignorados pelo homem que ao longo do tempo, como o crescimento populacional descontrolado e, por consequência, o maior do consumo de alimentos e matérias primas necessárias para a produção dos diversos itens indispensável para a sobrevivência do ser humano, esqueceu que os recursos do planeta é finito (MAGERA, 2015).

O desenvolvimento de técnicas para acelerar a produção, acentuou ainda mais os problemas relacionados à preservação do meio ambiente e sua sustentabilidade.

Estas consequências surgem como uma nova oportunidade das empresas explorarem um novo 'nicho' de mercado e seu potencial, como uma maneira de fortalecer e estreitar laços de relacionamento com um novo segmento de consumidores, preocupados e atentos com um olhar mais cuidadoso com o equilíbrio entre a sua saúde e a manutenção do planeta.

O presente estudo adota uma metodologia qualitativa que conforme Ludke \& Andre (2013; Koche, 2011) considera a multiplicidades de dimensões para um problema e traz possibilidades de explicação da realidade em relação ao fenômeno interpretado e compreendido.

\section{Consumo Sustentável}

Segundo o relatório Brundtland (1987) define consumo sustentável como o ato de adquirir, utilizar e descartar bens e serviços com respeito ao meio ambiente e à dignidade humana. Consumo Sustentável quer dizer saber usar os recursos naturais para satisfazer as nossas necessidades, sem comprometer as necessidades das gerações futuras. Para Ferreira (2010) é a condição ou qualidade de algo que pode se sustentar, defender, manter ou conservar. Com esse argumento, podemos caminhar para um sistema que diz respeito à integração indissociável (ambiental e humano), e avalia suas propriedades e características, abrangendo os aspectos ambientais, sociais e econômicos. 
Do ponto de vista de sobrevivência das empresas, esta passa a ter um novo desafio, o de manter a rentabilidade necessária para manter a saúde financeira em dia, mas com o olhar mais atento em um novo segmento, agora, mais consciente, mais informado e mais preocupado com o consumo mais responsável e sustentável para não comprometer o meio ambiente e as futuras gerações com a exploração inadequada dos recursos disponíveis.

Comprometer futuras gerações, podemos entender como o ato de fazer uso dos recursos naturais gerando a escassez. Desde 1970 o índice que contabiliza a quantidade destes recursos necessários para suprir as necessidades humanas vem crescendo em ritmo acelerado. A estimativa é feita pela Global Footprint Network (2019) que afirma que atualmente existe um saldo negativo e crescente em termos de consumo. Hoje é necessário1,75 planetas (quase dois planetas) para atender a esta necessidade básicas para a existência dos seres humanos. Assim, a mesma organização afirma que este consumo é maior do que a capacidade do planeta se regenerar, e que s consequências deste impacto está se tornando irreversível, tornando-se urgente a tomada de ações para corrigir este quadro. Não há espaço para negociarmos uma transformação lenta. O momento pede ações rápidas e efetivas.

\section{Consumo Verde}

A partir da conscientização da necessidade de consumo sustentável Portilho (2005) explica que o surgimento da ideia de que "um consumo verde e, portanto, de um consumidor verde, só foi possível, basicamente, a partir da conjunção de três fatores inter-relacionados: o advento, a partir da década de 1970, do ambientalismo público; a "ambientalização" do setor empresarial, a partir dos anos 1980; e a emergência, a partir da década de 1990, da preocupação com o impacto ambiental de estilos de vida e consumo das sociedades afluentes".

Portilho (2015) define o consumidor verde como:

O consumidor verde foi amplamente definido como aquele que, além da variável qualidade/preço, inclui em seu "poder de escolha", a variável ambiental, preferindo produtos que não agridam ou sejam percebidos como nãoagressivos ao meio ambiente. 1 Dessa forma, o movimento de consumo verde enfatizou a habilidade dos consumidores agirem em conjunto, trocando uma marca $\mathrm{X}$ por uma marca $\mathrm{Y}$, ou mesmo parando de comprar um determinado produto, para que os produtores percebessem as mudanças na demanda. As ações e as escolhas individuais motivadas por preocupações ambientais passaram a ser vistas como essenciais, e o consumidor como o responsável, através de suas demandas e escolhas cotidianas, por mudanças nas matrizes energéticas e tecnológicas do sistema de produção. No entanto, essa estratégia de "comprar um futuro melhor" acabou sendo rapidamente posta em questão, virando uma grande armadilha (Portilho, 2015).

O comportamento do consumidor vem sendo estudado pelas empresas como forma de aproximar, cada vez mais, a opção de compra das pessoas aos produtos/serviços ofertadas pelas grandes corporações. Solomon (2013), define o comportamento do consumidor como o estudo sobre como indivíduos, grupos e organizações selecionam, compram, usam e descartam bens, serviços, ideias ou experiências para satisfazer suas necessidades e desejos.

A participação corporativa aparece como uma parte fundamental neste processo de conscientização. Não basta apenas desenvolver processos amigos do meio ambiente, tampouco produtos sustentáveis, mas a comunicação precisa ter o fator educacional como forma de ajudar na transformação definitiva no que tange a consciência cultural de preservação da sociedade.

Neste contexto, a formação cidadã que preserve os valores ambientais passam em criar experiências diárias como forma de transformar hábitos antigos e aproximar a cultura ambiental em nosso dia a dia.

A comunicação nunca teve um momento tão especial e importante na história quanto agora, primeiramente, pelo caráter educativo e consequentemente, a importante função inclusiva dos consumidores em um novo cenário, como atores 
pertencentes a uma sociedade consciente, tornando-os mais responsáveis, mais saudáveis e mais próximos do meio ambiente. Esta comunicação educativa aproxima a todos os envolvidos nesta cadeia de valores e passa fornecer insumos para aos consumidores tomarem decisões mais assertivas em relação a sua importante participação neste ecossistema. Perguntas como: Por que comprar ? O quê comprar? Como comprar? De quem comprar? Como usar? E como Descartar (Figura 1). Estas questões podem auxiliar na formação de novos valores que incorporam o comportamento deste novo consumidor, mais participativo e engajado com suas responsabilidades neste importante processo de preservação.

Figura 1 - Princípios de um consumo consciente.

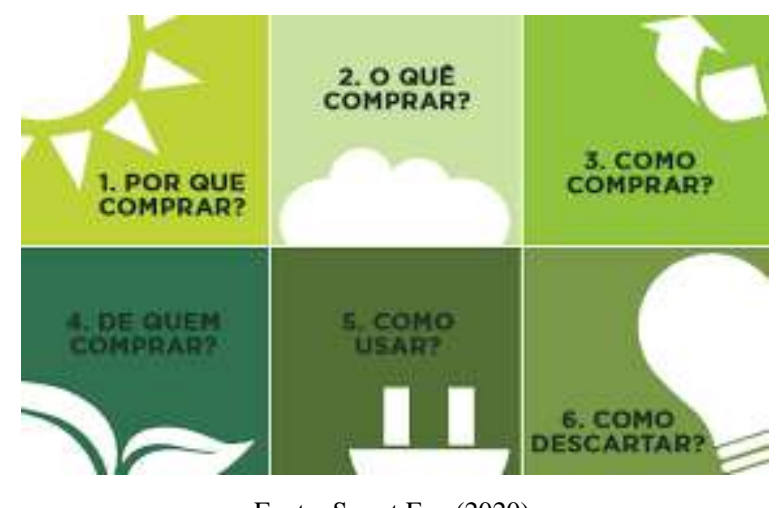

Fonte: Smart Eco (2020).

Desta forma, a empresa que faz uso responsável das estratégias de marketing como forma de acirrar a comunicação direcionada, aproximando os consumidores da informação necessária sobre os benefícios do consumo sustentável e não apenas melhorar a qualidade de sua saúde, mas também a melhoria do meio ambiente, assume seu lado responsável por orientar e fomentar a existência do consumidor verde.

Como já abordado anteriormente, este consumidor estará pronto para realizar escolhas mais conscientes e desta forma, mais adequadas à sustentabilidade, que irão promover a melhoria constante nos seus hábitos de consumo diários, oportunizando as empresas à comunicação efetiva sobre todas as etapas de um processo, apresentando, inclusive, todos os cuidados e a maneira responsável de atuação a cada momento da formação do produto e convidando este cliente a fazer parte deste projeto, como parte importante e fundamental que vai desde a escolha do melhor produto/marca/empresa, até mesmo, o descarte final. Uma forma atraente de gerar o comprometimento positivo e benefícios cada vez maiores ao meio ambiente e a preservação do ecossistema.

A íntima relação entre o consumidor verde e as empresas não irá retirar a soberania quanto a escolha feita por este novo personagem, mais informado, acrescido pelo respeito a esta decisão, agora, mais responsável e consciente de seu papel junto a solução deste problema latente a nossa sociedade.

Os contornos deste novo perfil de consumidor vêm no sentido de fortalecer o caráter maior de cidadania, a partir do momento em que os novos atores participam deste processo em prol do meio ambiente e acima de tudo, a comunicação vem no sentido de moldar estes personagens, a partir do sentimento de pertencimento de uma nova etapa de consumo mais consciente e responsável.

\section{Considerações Finais}

A nova realidade de consumo consciente, a partir das relações entre a responsabilidade ambiental das empresas e a mudança do comportamento dos consumidores, passa por um novo movimento importante na continuidade e preservação da vida em nosso planeta. Trazer a discussão sobre o confronto entre homem e meio ambiente, produz um novo tipo de ator neste 
contexto, o consumidor verde. Para garantir o sucesso desta nova parceria é necessário que haja um processo de educação e conscientização para que haja engajamento e comprometimento deste consumidor. A comunicação objetiva e inclusiva aparece como um fator de intima aproximação no que tange a seu uso como ferramenta de educação e informação para que possa unir estes dois atores em prol do bem comum e do meio ambiente.

As estratégias de comunicação e a propagação de ideias que tragam o consumo sustentável tornaram-se urgente e imediata pelo momento delicado pelo qual passamos. Como apontado nesta pesquisa, o saldo negativo deixado ao longo do tempo e o retrocesso causado pelo consumo exagerado devido as necessidades humanas atendidas em desequilíbrio com o meio ambiente, acelera o processo necessário para utilizar a educação como forma de atrair e desenvolver este novo perfil de consumo (verde) e desta forma, preservar o planeta e a vida que nele se encontra.

Para isso, a utilização das várias ferramentas de estratégia de conscientização, potencializadas pelos diversos recursos, canais e redes de comunicação, traz o consumidor para o envolvimento participativo sobre as questões inerentes aos grandes desafios de recuperar o meio ambiente.

Por fim, é necessário criar rotinas que não podem ser silenciosas, mas sim, uma ampla contribuição de todos os atores no que concerne à preservação dos recursos naturais, com um intenso envolvimento, por meio de uma comunicação que gera novos valores comportamentais, como forma de aumentar o engajamento entre todos os interessados, e acima de tudo, um comprometimento participativo e fomentar um espaço de crescimento do multiplicador de informações e dos bons hábitos de consumo, na intensa causa de criarmos uma relação, cada vez mais saudável, para os consumidores, empresa, meio ambiente e sustentabilidade.

\section{Referências}

Adams, W. M. (2006). The Future of Sustainability: Re-Thinking Environment and Development in the Twenty-First Century. Gland, Switzerland: World Conservation Union.

Bergamini, C. W. (1989). Motivação. 2ed. Atlas.

Chiavenato, I. (1997). Recursos Humanos. Edição compacta. 4ed. Atlas.

Calomarde, J. V. (2000). Marketing ecológico. Madrid: Pirâmide.

Dubrin, A. J. (2003a). Fundamentos do comportamento organizacional. São Paulo: Pioneira Thomson Learning.

Dubrin, A. J. (2003b). Marketing ecológico. Pirâmide. Dubrin, A. J.

Ecodebate. (2021). Consumo sustentável. Publicado no website Ecodebate. https://www.ecodebate.com.br/2011/08/31/consumo-sustentavel-artigo-de-ricardomachado/.

Globo.com. (2019). Sobrecarga da terra 2019: planeta atinge esgotamento de recursos naturais mais cedo em toda a série histórica. Website G1 Globo.com. https://g1.globo.com/natureza/noticia/2019/07/29/sobrecarga-da-terra-2019-planeta-atinge-esgotamento-de-recursos-naturais-mais-cedo-em-toda-a-seriehistorica.ghtml.

Koche, J. C. (2011). Fundamentos de metodologia científica. Petrópolis: Vozes. Disponível em: http://www.brunovivas.com/wpcontent/uploads/sites/10/2018/07/K\%C3\%B6che-Jos\%C3\%A9-Carlos0D0AFundamentos-de-metodologia-cient\%C3\%ADfica-_teoriada0D0Aci $\%$ C3\%AAncia-e-inicia\%C3\%A7\%C3\%A3o-\%C3\%A0-

pesquisa.pdfhttps://repositorio.ufsm.br/bitstream/handle/1/15824/Lic_Computacao_Metodologia-Pesquisa-Cientifica.pdf?sequence=1

Ludke, M. \& Andre, M. E. D. A. (2013). Pesquisas em educação: uma abordagem qualitativa. E.P.U.

Magera, M. C. (2011). Os empresários do lixo: um paradoxo da modernidade. Editora Átomo Alinea.

Magera, M. C. (2015). Os caminhos do lixo: Da obsolescência programada a logística reversa. Ed. Átomo Alinea.

Magera, M. C. (2021). Viabilidade econômica da reciclagem dos resíduos domésticos da cidade de Coimbra - utilizando o aplicativo verdes-PT. RECIMA21 Revista Científica Multidisciplinar - ISSN 2675-6218, 2(2), 427-440. https://doi.org/10.47820/recima21.v2i2.103.

Manzini, E. \& Vezzoli, C. (2005). O Desenvolvimento de Produtos Sustentáveis: os requisitos ambientais dos produtos industriais. Edusp.

Maximiniano, A. C. A. (2000). Teoria Geral da Administração: da escola científica à competitividade globalizada. 2. ed. São Paulo: Atlas, 2000.

Montana, P. J. \& Charnov, B. H. (1998). Administração. Ed.Saraiva. 
Research, Society and Development, v. 10, n. 8, e48910817634, 2021

(CC BY 4.0) | ISSN 2525-3409 | DOI: http://dx.doi.org/10.33448/rsd-v10i8.17634

Pisani, J. A. (2006). Sustainable development - historical roots of the concept. Environmental Sciences. 3(2), 83-96.

Portilho, Fátima. Consumo sustentável: limites e possibilidades de ambientalização e politização das práticas de consumo. FGV 2005.

Relatório Brundtland (1987). Report of the World Commission on Environment andDevelopment: Our Common Future. Nações Unidas 1987.

Smart Eco. (2020). 15 de Outubro - Dia do consumo consciente, mas afinal, o que é ser um consumidor consciente? Website Smart Eco. https://smarteco.com.br/blog/15-10-2020/principios-para-um-consumo-consciente

Solomon, Michel R. O Comportamento do consumidor: comprando, possuindo e sendo. 9.ed. Porto Alegre: Bookman, 2013 